\title{
PERCEPCIÓN Y MANEJO DEL PAISAJE Y DE LOS RECURSOS VEGETALES POR CAMPESINOS TRASHUMANTES DE IRUYA (SALTA, ARGENTINA)
}

\author{
Perception and management of landscape and vegetable resources by trashumants cattle \\ farmers from Iruya (Salta, Argentina)
}

LAURA M. CALIFANO ${ }^{1}$ (D)

\begin{abstract}
Resumen: Se realiza un aporte actualizado al conocimiento referido al manejo altitudinal del ambiente y su relación con la percepción del paisaje y los recursos vegetales por parte de ganaderos trashumantes, en un área de la cordillera oriental del NW de la provincia de Salta. Los habitantes locales pertenecen a pueblos originarios de filiación étnica Kolla y presentan características socioeconómicas afines a la categoría campesino. Las unidades domésticas presentan una movilidad estacional vinculada a la trashumancia del ganado bovino entre los ambientes de Yungas y Altoandino presentes en los distintos pisos altitudinales a los que tienen acceso. A partir de un abordaje etnobiológico se registraron las principales unidades ambientales implicadas en el manejo anual, las etnoespecies presentes, sus usos y las prácticas sociales y productivas vinculadas a la conformación de un paisaje cultural.
\end{abstract}

Palabras clave: Diversidad biocultural, Etnobiología, manejo vertical, recursos vegetales, unidades ambientales.

\begin{abstract}
Summary: An updated contribution to the knowledge on the altitudinal management of the environment and its relationship with the perception, use and management of plant resources by transhumant cattle farmers, in an area of the eastern mountain range of the NW of the province of Salta. The local inhabitants belong to indigenous peoples of the Kolla ethnic affiliation and present socio-economic characteristics related to the peasant category. The domestic units have a seasonal mobility linked to the transhumance of cattle between the Yungas and Altoandino environments present at the various altitudinal floors to which they have access. Based on an ethnobiological approach, the main environmental units involved in the annual management, the ethnospecies present, their uses and associated practices were recorded.
\end{abstract}

Key words: Biocultural diversity, environmental units, Ethnobiology, plant resources, vertical management.

\section{Introducción}

El manejo trashumante de ganado es una práctica tradicional que aún se encuentra en sociedades pastoriles en los ambientes cordilleranos y precordilleranos de los Andes de la Argentina. Desde la región patagónica hasta el NW del país se ha abordado su estudio y sistematización, con el objetivo de ampliar el conocimiento sobre su funcionamiento (Bocco de Abeyá, 1988; Bendini et al., 1993, 2004; Greco, 1995; Galafassi, 1994; Escolar, 1996; Maffia et Zubrzycki, 1999).

La trashumancia constituye una forma productiva particular de zonas con clima mediterráneo frío, en el cual los pastores realizan un movimiento recurrente, pendular $\mathrm{y}$ funcional, cuya periodicidad está regulada

\footnotetext{
${ }^{1}$ Instituto Nacional de Tecnología Agropecuaria, Estación Experimental Agropecuaria Abra Pampa, Agencia de Extensión Rural Humahuaca (Jujuy, Argentina). E-mail: califano.laura@inta.gob.ar / laucalifano@gmail.com
} 
por el ritmo cíclico de las estaciones y las actividades desarrolladas por las unidades domésticas (Bendini et al., 2004). En el NW del país, la trashumancia se desarrolla en diferentes modalidades y se observa usualmente como un movimiento periódico entre tierras ubicadas a distintas altitudes, en busca de disponibilidad de pasturas y agua en diferentes momentos del año. Este sistema se ha registrado en toda el área de la Cordillera Oriental de Jujuy y Salta, siendo el ganado vacuno el de mayor movilidad altitudinal y distancia de recorrido (Sturzenegger, 1982; Merlino et Rabey, 1983; Levy Hynes, 1994; Reboratti, 1998; Hilgert, 1998, 2007a; Hocsman, 2011; Quiroga Mendiola, 2000; Echazú et al., 2016).

Asociado a la trashumancia, se despliega un conjunto de conocimientos tradicionales vinculados al uso y manejo de los recursos vegetales, tanto silvestres como cultivados (Levy Hynes, 1994; Hilgert, 2001, 2004, 2007b; Califano et Echazú, 2013). Los pastores a partir de sus conocimientos ecológicos sobre el entorno aplican una clasificación a los ambientes por los cuales se desplazan. Este cuerpo de saberes fue construido alrededor de las percepciones ambientales y del conocimiento histórico referido a los recursos naturales a diferentes escalas de paisaje (Cotton, 1996; Mapinduzi et al., 2003; Scarpa, 2007). Son conocimientos resultantes de la cotidianeidad, de la necesidad de resolver la subsistencia a través del uso y del manejo de los recursos de cada unidad ambiental. Las percepciones y valores que cada población posee sobre sus paisajes pueden variar temporal y espacialmente, por ello, los paisajes culturales son producto de prácticas humanas y varían con los valores y la percepción temporal y espacial de cada grupo cultural (Toledo, 2002; Toledo et Barrera Bassols, 2008; Capparelli et al., 2011).

Durante el período prehispánico las sociedades andinas eran en parte ganaderas, articulaban la agricultura con la cría de camélidos para trasporte, consumo y obtención de fibra y cuero para sus vestimentas (Reinoso et Ruthsatz, 1982; Nielsen, 1996; Yacobaccio et al., 1998). El ya clásico modelo de control vertical planteado por Murra (1975) para las áreas montañosas de los Andes, señala que la práctica de atravesar y aprovechar diferentes pisos altitudinales existe desde tiempos pre-colombinos. Es en tal sentido que la trashumancia puede ser considerada como una práctica humana de manejo del paisaje, según lo planteado por los abordajes referidos a los paisajes culturales (Davidson-Hunt et Berkes, 2003; Toledo et Barrera Bassols, 2008).

Fue desde el inicio de la colonia que se produce la instauración de un nuevo régimen de explotación y producción, que introduce nuevos cultivos y el ganado de origen europeo (Capparelli et al., 2011). Es entonces que se difunde la crianza de bovinos con el objeto de introducir las nuevas tecnologías de labranza (arado a tracción animal) asociadas a los cultivos promovidos por los españoles, modificando las técnicas de labranza prehispánicas. Tal es así, que el manejo de los bovinos se ajustó a las condiciones ecológicas locales, sociales, económicas y culturales de las familias rurales de muchas zonas andinas perdurando hasta la actualidad (Hooft, 2004).

Se busca comprender la forma en que esta sociedad ve, percibe y ordena su entorno natural; y conocer el conjunto de prácticas, conocimientos y creencias involucradas, que surgen del accionar individual y social (Toledo, 2002; Albuquerque et al., 2019). Se entiende que la relación entre los recursos naturales y el desarrollo de estos sistemas de vida surge del planteo de que las dimensiones culturales y biológicas son inseparables, como lo abordan los enfoques centrados en la diversidad biocultural. Se considera a la diversidad biocultural como parte de los modos de hacer localmente situados, fundados en el conocimiento ambiental tradicional y que son de construcción comunitaria. Estos modos de hacer se encuentran basados en la oralidad, y se ponen de manifiesto en prácticas y tecnologías, dando lugar a capacidades técnicas que se gestionan de forma comunitaria o individual (Toledo et Barrera Bassols, 2008; Lema et Pochettino, 2012; Bartl, 2019).

En este trabajo se analiza la clasificación ambiental local, de los diferentes espacios o paisajes, las actividades agropecuarias que los campesinos realizan en ellos y su relación con un paisaje cultural históricamente construido. Se reconocen las prácticas y formas actuales 
de uso de los espacios ambientales y sus recursos vegetales. Para ello se emplea el concepto de Unidades de Paisaje (UP) que permite especificar espacios geográficos ecológicamente homogéneos, reconocidos y diferenciados por los propios productores (Zonneveld, 1989; Grimaldi et Trillo, 2018; Capparelli et al., 2011).

\section{Área de estudio}

El área de estudio se encuentra en el municipio de Iruya en el NW de la provincia de Salta, Argentina (Fig. 1). Comprende dos unidades geográficas o morfo-estructurales: la Cordillera Oriental (CO) y las Sierras Subandinas (SSA) ambas con orientación aproximada N-S y de altitud decreciente de W a E. La CO comprende las serranías de Santa Victoria y Zenta, que alcanzan los $5000 \mathrm{~m}$; mientras que las SSA son más bajas y alcanzan los $1400 \mathrm{~m}$. La CO constituye un importante límite orográfico que con un gran salto altitudinal separa al $\mathrm{W}$ el altiplano de la región de Puna, de los valles bajos templados del E de Salta (Reboratti, 1998).
Las laderas $\mathrm{W}$ de la $\mathrm{CO}$ están cubiertas por extensos pastizales y por una estepa de arbustos muy similar a la que se extiende en la Puna; mientras que las SSA se caracterizan por estar cubiertas por la denominada Selva Nublada. Ambas cadenas montañosas confieren al relieve características escarpadas y conforman valles fluviales de orientación W-E, que constituyen corredores o vías que vinculan tres ambientes: la Puna, los valles de altura intermedios y las Yungas o Selvas Subtropicales de Montaña. El área además pertenece al sistema hidrográfico de la Alta Cuenca del Río Bermejo, dentro del cual el río Iruya es relevante por su recorrido de $125 \mathrm{~km}$ desde sus nacientes a los $5000 \mathrm{~m}$ y su desembocadura en el río Pescado a solo 450 m, en un desnivel de 4000 m (Reboratti, 1998; Raffaelli et Pérez Ayala, 1999).

El clima es semiárido de alta montaña en los sectores altos y subtropical con estación seca en las zonas bajas, con una importante variación debido al abrupto gradiente altitudinal, característica propia de los sistemas montañosos subtropicales, donde las diferencias de altura dan lugar a fuertes

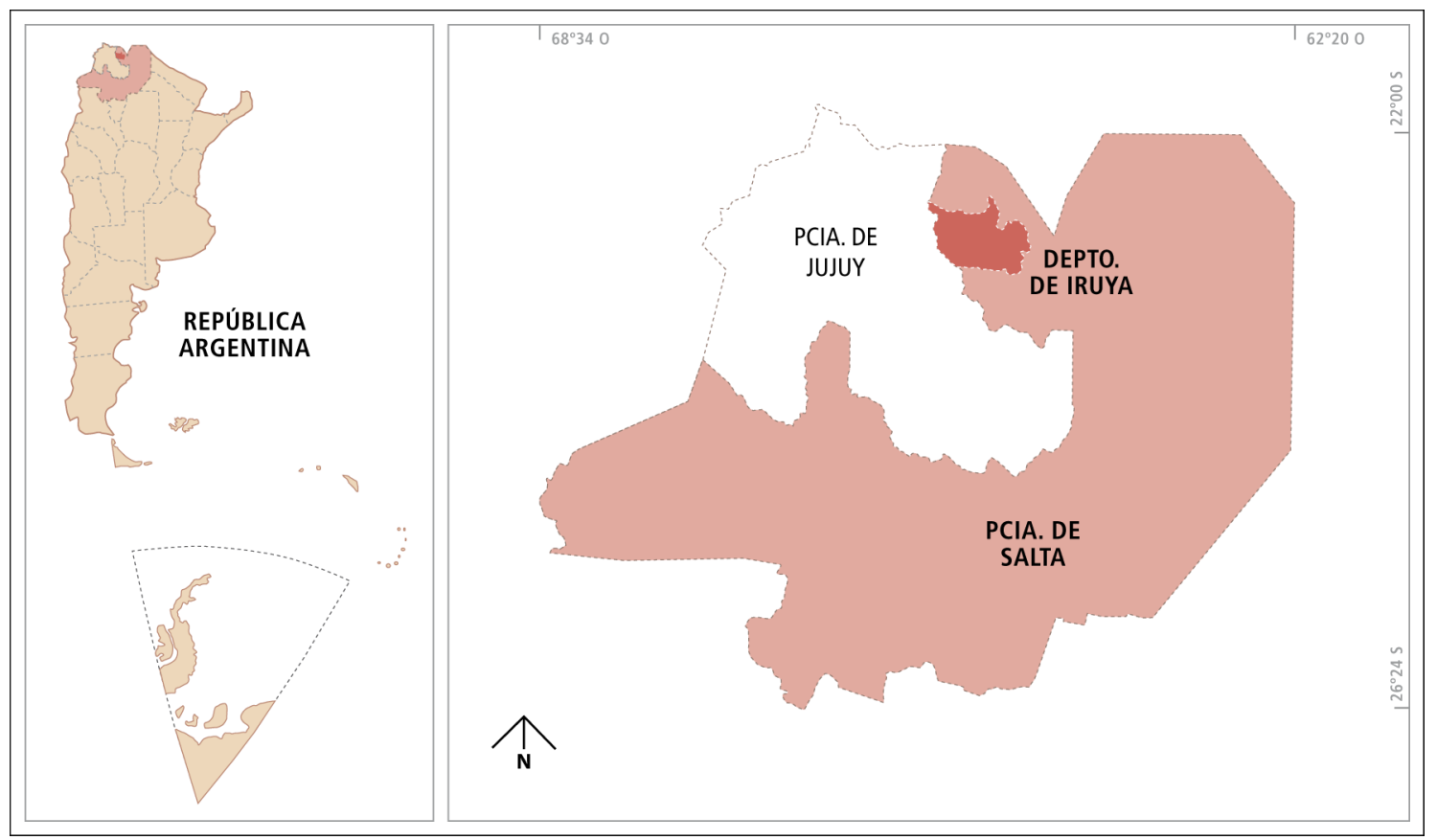

Fig. 1. Ubicación del departamento de Iruya en la provincia de Salta, Argentina.

Fig. 1. Location of the department Iruya in the province of Salta, Argentina. 
diferencias climáticas. Para una altitud media de $2500 \mathrm{~m}$ la temperatura media máxima oscila entre 16 y $28^{\circ} \mathrm{C}$, y la media mínima entre 8 y $15^{\circ} \mathrm{C}$. Pero, a partir de los $3400 \mathrm{~m}$ la temperatura media está entre 7,5 y $9,9^{\circ} \mathrm{C}$, el clima se vuelve más frío y seco por efecto de los vientos y la altura (Bianchi et Yañez, 1992; Reboratti, 1998; Raffaelli et Pérez Ayala, 1999).

El régimen de precipitaciones es influenciado por la orografía y varía en un gradiente que disminuye de $\mathrm{E}$ a $\mathrm{W}$ con $1200 \mathrm{~mm} / \mathrm{año}$ en Yungas, a $400 \mathrm{~mm} / \mathrm{año}$ en Puna y Altoandino. Se presenta un patrón anual con una estación húmeda (octubre-abril) y una estación seca (mayo-setiembre). La formación de un techo nuboso en el E, sobre pendientes medias (1500 a $2000 \mathrm{~m})$, es casi una constante aún en invierno (junio-setiembre) (Bianchi et Yañez, 1992; Reboratti, 1998).

No existe un criterio consensuado sobre la clasificación fitogeográfica de estos valles; para Reboratti (1998) es un ejemplo de las denominadas Cordilleras Subtropicales (Troll, 1973) porque las laderas del E se encuentran cubiertas por bosques y las de orientación $\mathrm{W}$ poseen paisajes áridos o semidesérticos. Se observa claramente que el área constituye una zona de convergencia de provincias fitogeográficas con elementos vegetales de diferentes formaciones. Parte de la zona pertenece a la provincia fitogeográfica de Yungas, Selvas Subtropicales de Montaña o Selvas Tucumano-Oranenses (Ragonese, 1967; Cabrera, 1976; Cabrera et Willink, 1980). En el límite inferior de las Yungas $(450-550 \mathrm{~m})$ se inicia la transición con las formaciones chaqueñas, y en su límite superior (aprox. $2700 \mathrm{~m}$ ) ecotonos con formaciones pertenecientes a las provincias Prepuna, Puna y Altoandina. Hay zonas de transición donde coexisten especies y formaciones de uno y otro piso de acuerdo a la orientación de las laderas y valles. El único límite neto constituye la línea de bosque de aliso del cerro (Alnus acuminata Kunth) en el deslinde con el pastizal de altura a los 2800 m (Reboratti, 1998).

\section{Características socioeconómicas}

El departamento Iruya comprende dos municipios: Iruya e Isla de Cañas, cada uno con diferentes vías de acceso (Fig. 2). La jurisdicción del municipio Iruya se restringe a las zonas de mayor altitud del departamento, alrededor de los $2780 \mathrm{~m}$, mientras que el municipio de Isla de Cañas se encuentra por debajo de los $610 \mathrm{~m}$. Entre ambos municipios no existe una red vial que permita su comunicación directa, por lo cual se trata de un territorio con un importante aislamiento geográfico y comunicacional, rasgo sobresaliente del área.

La población del departamento Iruya es de 5987 habitantes y representa aproximadamente el 0,7 del total de la provincia de Salta, con una densidad poblacional de $1,7 \mathrm{hab} . / \mathrm{km}^{2}$. Se considera rural en su totalidad al no existir localidades con más de 2000 habitantes (según los criterios del INDEC) y posee uno de los mayores índices de necesidades básicas insatisfechas (NBI) de la provincia (INDEC, 2010).

Las comunidades de Iruya poseen características similares a las sociedades campesinas, ya que la unidad doméstica de producción se basa fundamentalmente en la combinación de trabajo familiar y tierra; cuyo límite es el punto en el que comienza un proceso de acumulación de capital, o predomina la venta de mano de obra fuera del predio (Reboratti, 1998; Hocsman, 2011; Quiroga Mendiola, 2000; Echazu et al., 2013, 2016). Los criterios usuales que se emplean para diferenciar las unidades campesinas son: a) uso preponderante de la mano de obra familiar en el predio, b) acceso limitado a los recursos tierra y capital, c) relación de subordinación con los mercados y d) otros criterios como, aversión al riesgo, bajo desarrollo tecnológico y diversidad de actividades prediales (Tsakoumagkos, 1993; Cáceres, 2003). La división de las comunidades guarda una estrecha relación con las haciendas coloniales que dieron lugar a la definición de las unidades político administrativas actuales (Reboratti, 1998).

La economía local se caracteriza por producir bienes agropecuarios destinados a satisfacer las necesidades de subsistencia a través de la producción agrícola, ganadera y las producciones artesanales (textiles, cueros, carpintería, entre otras). Cada familia posee un espacio propio para la agricultura 


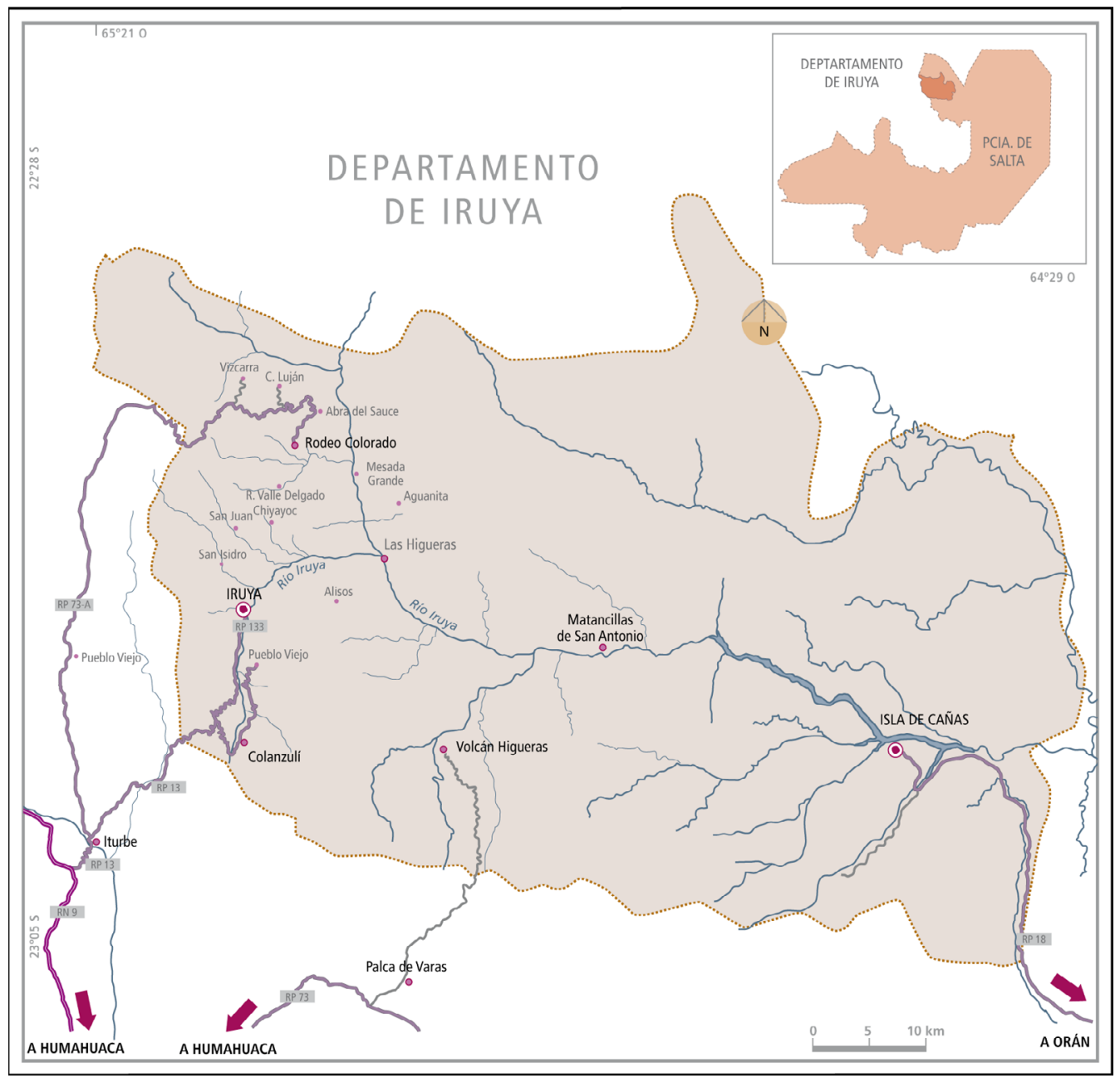

Fig. 2. Localización de los municipios de Iruya e Isla de Cañas en el departamento de Iruya, vías de acceso e hidrografía. Fig. 2. Location, access roads and hydrography of the municipalities of Iruya and Isla de Cañas.

complementado con espacios dedicados a granja y crianza de ganado. La ganadería está representada por dos hatos diferenciados: el ganado bovino y el ganado menor (Echazu et al., 2013, 2016). La diversidad es el rasgo principal de la producción de tipo campesina andina, porque la variedad en sí misma es un mecanismo para reducir el riesgo que imponen estos ambientes, que por sus características ambientales limitan las posibilidades productivas (Ríos Ocsa, 1992; Toledo, 1992; Göbel, 2001, 2002; Hooft, 2004).

La lengua actual del poblador local es el español, pero en la fitonimia, toponimia y el léxico cotidiano se advierten voces provenientes del aymara y del quechua. La religión dominante es el catolicismo presente en sincretismo con creencias prehispánicas andinas; se observan en menor medida otros cultos como la Iglesia Evangélica o los Testigos de Jehová (Califano, 2019).

\section{Materiales y Métodos}

Se empleó una metodología etnobiológica, que implica la permanente apertura del investigador a todas las manifestaciones del sistema biocultural, tal como se presenta en la vida cotidiana de los actores abordado desde su perspectiva (Baptista Lucio et al., 2006; Martínez, 2006; Arenas et Martínez, 2012). 
La recopilación de información se realizó en 14 comunidades del municipio de Iruya en el período de enero de 2011 a diciembre 2017, por medio de técnicas etnográficas: reuniones y talleres con pobladores e informantes calificados, entrevistas exploratorias y en profundidad a informantes clave, recorridas de campo con informantes para colecta de muestras vegetales y observación participante (en ferias, eventos rituales y actividades agropecuarias). Los datos e información se registraron en notas de campo, grabaciones y fotografías. Se tomó como unidad de análisis las unidades domésticas (UD). La Unidad Doméstica se define como un grupo de personas que interactúan en forma cotidiana, regular y permanente, a fin de asegurar mancomunadamente el logro de los siguientes objetivos: su reproducción biológica, la preservación de su vida, el cumplimiento de todas aquellas prácticas económicas y no económicas indispensables para la optimización de sus condiciones materiales y no materiales de existencia (Archetti et Stolen, 1975; Torrado, 1981; Cáceres, 2003).

Para las entrevistas se confeccionó una guía temática con tópicos referidos al manejo y uso del espacio, de los recursos vegetales, de la ganadería, los significados y percepciones. La duración promedio de las entrevistas fue de 3060 minutos; en su mayoría individuales (94\%) y en algunos casos se sumó otro participante interesado. El 69\% de los informantes fueron hombres, debido a que la actividad ganadera bovina concentra la mano de obra masculina. En total, se trabajó con 45 informantes, en un rango de 30 a 85 años de edad y de diferentes niveles de instrucción.

Se estableció como criterio de consenso para validar la información recopilada que al menos dos informantes indicaran sobre el mismo uso de determinada especie vegetal o de otros aspectos de manejo consultados en la entrevista (Scarpa, 2000; Suárez, 2014). En cuanto a los datos etnobotánicos, se procedió a una comparación bibliográfica con fines de corroborar la existencia de menciones similares para la zona y áreas adyacentes.

Para el análisis de los datos etnobotánicos se construyeron once categorías de uso; y se partió de una noción de categoría de uso no en sentido estricto, dado que se incorpora tanto la finalidad como el manejo (por ejemplo, esto lleva a la distinción entre forrajeras silvestres y forrajeras cultivadas). Se busca reflejar todo el abanico de usos y manejos relevados. En caso de que una especie tenga más de un uso se la ha incluido, en primer lugar, en la categoría en la cual es más relevante y luego en las restantes. Se emplea el término etnoespecies o etnotaxa para representar a los elementos vegetales que son funcionales a las preferencias de uso de esta sociedad y a las necesidades locales; conjuntamente con el término etnovariedades para referir los diferentes tipos locales dentro del mismo taxón (Sánchez et al., 2007; Rosales Bustamante et al., 2009; Lambaré et Pochettino, 2012).

La identificación de especies fue realizada con el soporte de las bases de Tropicos.org (Missouri Botanical Garden, 2019), Flora del Cono Sur - Flora Argentina (IBODA, 2018), The Plant List (TPL, 2013). La colección de referencia se depositó en el Herbario del Museo de Ciencias Naturales de Salta (MCNS). La colección se complementó con muestras de materiales vegetales en las diferentes formas en que son adquiridos, consumidos e intercambiados para su uso; y en ausencia de elementos fértiles se obtuvieron propágulos para su cultivo (Arenas et Kamienkowski, 2014).

\section{Resultados}

Para los productores de Iruya el paisaje se resume en dos principales UP diferenciables entre sí, el cerro y el monte, aplicando como criterio de separación la presencia de árboles que dan lugar a la formación de un bosque o una selva. Por ello el monte se corresponde a los pisos ecológicos de Selva Montana y Bosque Montano de las Yungas; mientras que el cerro se corresponde con los pastizales de altura y las estepas de Puna y Prepuna. Se destaca la definición de una tercera UP que es de localización intermedia entre cerro y monte denominada valle. Se localiza en sectores altos $(2500 \mathrm{~m})$ y se la reconoce por ser cálida, húmeda y carecer de árboles; corresponde al pastizal de altura o de neblina de la Yungas. Estos espacios se encuentran 
a diferentes altitudes, por lo que poseen distintos tipos de formaciones vegetales, que influyen en las actividades que se realizan en cada uno de ellos (Tabla 1). Así como los espacios de cerro y de monte estructuran el ciclo ganadero, el año es dividido en dos épocas, la lluviosa (noviembre-abril) y la seca (mayo-octubre). La combinación de estos dos aspectos (altitud y períodos de lluvias) está estrechamente relacionada con la trashumancia como estrategia de uso vertical del ambiente. Establecen otro tipo de diferenciación temporal denominada tiempos, que hace referencia a acontecimientos puntuales relacionados a aspectos ambientales y de manejo. De tal forma existen los tiempos de llevar las vacas y de sacar las vacas, los tiempos en que se cría el pasto (tanto en el cerro como en el monte), tiempos de echar terneros (fecha en que se concentran las pariciones), tiempos de ir a dar la sal (en referencia a la práctica de dar sal como suplemento a los bovinos).

Las UD poseen varias residencias, la mayoría de las veces en más de tres sitios de pastoreo. Las residencias se diferencian en permanentes o temporales, y una de ellas funciona como principal, en la que se habita de forma estable. Las viviendas permanentes presentan una mejor construcción, mientras que las temporales se denominan puestos y se asemejan a un refugio. Por ser construcciones temporarias, el período de residencia puede abarcar desde semanas a algunos meses; por este motivo son extremadamente rudimentarios y suelen ser construidos en el momento en que serán utilizados.

Los parajes donde están los puestos de cada UD se encuentran establecidos de manera consuetudinaria y su ubicación está relacionada al pastoreo; la permanencia es temporal -mientras hay forraje disponible- para luego desplazarse a otro puesto. En el monte son muy pocas las UD con casas estables, solamente poseen puestos temporales. Como las comunidades de cerro y de valle cuentan con mejores servicios de comunicación son las más pobladas; allí se construyen las viviendas donde la UD establece su residencia principal.

En ese contexto, el uso vertical de los ambientes toma como centro el sitio de residencia permanente de la UD, situado usualmente en las comunidades de cerro.

Tabla 1. Los ambientes, sus características y actividades predominantes.

Table 1. Characteristics of environments and predominant activities.

\begin{tabular}{|c|c|c|c|c|}
\hline $\begin{array}{l}\text { Clasificación } \\
\text { Local }\end{array}$ & $\begin{array}{l}\text { Altura } \\
\mathrm{m}\end{array}$ & Relieve & $\begin{array}{l}\text { Formas de vida y } \\
\text { Tipo de ambiente }\end{array}$ & $\begin{array}{l}\text { Actividades } \\
\text { predominantes }\end{array}$ \\
\hline "Cerro" & $3000-4000$ & $\begin{array}{l}\text { Filo de los } \\
\text { "cerros". }\end{array}$ & $\begin{array}{l}\text { Herbáceas. Praderas bajas. } \\
\text { Gramíneas y arbustos bajos. }\end{array}$ & $\begin{array}{l}\text { Ganadería de rumiantes } \\
\text { menores. Ganadería } \\
\text { bovina en verano. } \\
\text { Agricultura. }\end{array}$ \\
\hline "Valle" & $2000-3000$ & $\begin{array}{l}\text { Medio filo o } \\
\text { ladera. }\end{array}$ & $\begin{array}{l}\text { Herbáceas. Arbustivas. } \\
\text { Praderas de gramíneas con } \\
\text { arbustos y bromeliáceas } \\
\text { forrajeras. }\end{array}$ & $\begin{array}{l}\text { Ganadería de rumiantes } \\
\text { menores. Agricultura. } \\
\text { Ganadería bovina en } \\
\text { verano. Recolección } \\
\text { de leña y aromáticas y } \\
\text { medicinales. }\end{array}$ \\
\hline "Monte chico" & $2000-1500$ & $\begin{array}{l}\text { Medio filo } \\
\text { y laderas } \\
\text { bajas. } \\
\text { Faldeos. }\end{array}$ & $\begin{array}{l}\text { Herbáceas. Arbustivas. } \\
\text { Transición donde comienzan } \\
\text { árboles bajos de Alnus, } \\
\text { Prosopis. }\end{array}$ & $\begin{array}{l}\text { Ganadería bovina en } \\
\text { invierno. Recolección } \\
\text { de leña y aromáticas y } \\
\text { medicinales. }\end{array}$ \\
\hline "Monte" & < a 1500 & $\begin{array}{l}\text { Piedemontes } \\
\text { y terrazas. }\end{array}$ & $\begin{array}{l}\text { Herbáceas. Arbustivas. } \\
\text { Arbóreas. Epífitos. }\end{array}$ & $\begin{array}{l}\text { Ganadería bovina en } \\
\text { invierno. Recolección de } \\
\text { leña, de aromáticas y } \\
\text { medicinales. Recolección } \\
\text { de maderas. }\end{array}$ \\
\hline
\end{tabular}


A grandes rasgos, dos son los aspectos que influyen en la decisión de la UD sobre qué tipo de ganado criar: a) la localización de los puestos, y b) la disponibilidad de mano de obra dentro de la UD. Si posee solamente puestos en el ambiente de cerro, la UD se vuelca a la crianza de ovinos y/o caprinos. En caso de contar con puestos en el valle y/o el monte pueden incluir la producción bovina. En cuanto a la disponibilidad de mano de obra, si la UD está integrada por mujeres solas con niños, es más probable que elijan criar ovinos y/o caprinos, mientras que la cría de bovinos es más usual si hay integrantes masculinos.

El esquema de trashumancia que se practica en Iruya integra un gradiente mayor a los 2000 m, está basado en el cambio de lugar de pastoreo del ganado bovino entre dos o más sitios en diferentes UP; localizados en el cerro y en el monte (Fig. 3). Este manejo permite el aprovechamiento de los recursos vegetales de los distintos pisos altitudinales en diferentes períodos, atenuando el bache forrajero de la estación seca, así como el descanso y recuperación de los ambientes pastoreados. El desplazamiento de los ganaderos con los animales lleva de dos a tres días de recorrido a pie, en trayectos totales de aproximadamente 30 $\mathrm{km}$ de distancia. El esquema de trashumancia que más se ha perdido es el de trasladar toda la UD para residir temporariamente (seis meses) en los parajes de monte, llevando consigo bovinos y rumiantes menores.

Las actividades agrícolas se concentran en el cerro y el valle; mientras que en el monte se desarrollan principalmente actividades de recolección. El período agrícola se inicia en agosto, mes altamente significativo, porque concentra los rituales a la Pachamama en los cuales se agradecen las cosechas y se solicita un buen período para el año agrícola que comienza.

La época de labrar el suelo y de las siembras es la primavera (setiembre-noviembre), al final del verano (febrero-marzo) son las cosechas.

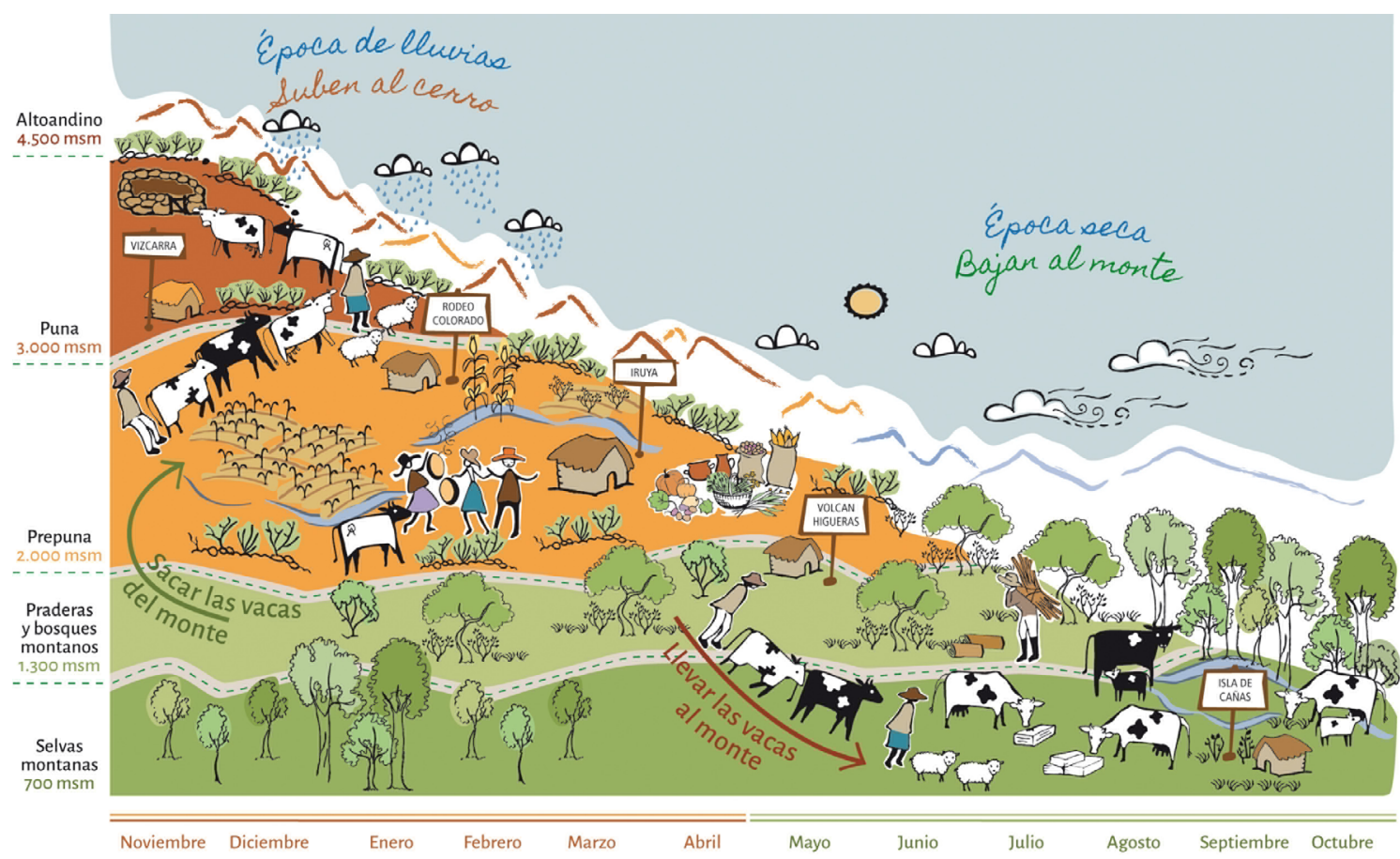

Fig. 3. Esquema de la trashumancia que se practica en Iruya, basada en el cambio de lugar de pastoreo del ganado bovino entre dos ambientes.

Fig. 3. Scheme of transhumance practiced in Iruya, based on the change of cattle grazing place between two environments. 
En otoño (abril-mayo) se concentran las actividades de venta e intercambio de los productos cosechados. Estos se preparan para el almacenamiento a través de técnicas tradicionales, como secar y acondicionar los granos y los tubérculos, preparar y separar lo que se utilizará como semillas. Las diferentes técnicas de conservación de los productos agrícolas implican clasificación y posterior secado al sol, ya sea en cestas o sobre enramados, o directamente en el suelo (Fig. 4). Además, se acondicionan los forrajes y restos de cultivos que servirán de alimento del ganado, se arman las calchas de maíz (Zea mays L.), que consisten en cortar y armar parvas con los restos de las plantas para completar su secado; la alfalfa (Medicago sativa L.) se corta y se acomoda en hileras para su secado. En las parcelas quedan los restos de los cultivos en pie para ser utilizadas como potreros para el pastoreo directo de los animales (abril-agosto).

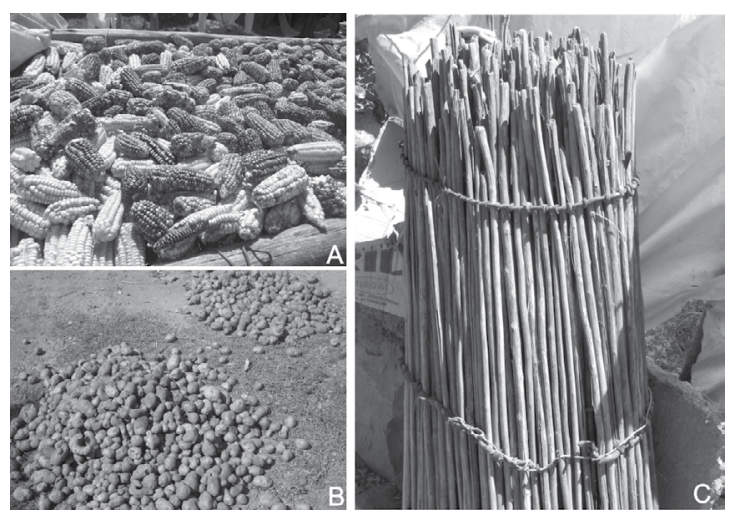

Fig. 4. Técnicas de conservación de productos agrícolas. A: Etnovariedades de maíz (Zea mays L.) sobre enramada para su clasificación y secado al sol. B: Clasificación y secado al sol de papas andinas [Solanum tuberosum subsp. andigena (Juz. \& Bukasov) Hawkes]. C: Cestos artesanales realizados con varas de "guaranguay" (Tecoma garrocha Hieron.) empleados para secar tubérculos.

Fig. 4. Conservation techniques for agricultural products. A: Conservation techniques for agricultural products. Sun drying and classification to conservation of potatoes [Solanum tuberosum subsp. andigena (Juz. \& Bukasov) Hawkes]. B: Ethnovariety of corn (Zea mays L.) for classification and drying in the sun. C: Handcrafted baskets made of "guaranguay" (Tecoma garrocha Hieron.) sticks used to dry tubers.
Para la agricultura se emplean parcelas -de 0,5 ha o mayores- denominadas rastrojos que pueden ubicarse alejadas de las casas. Entre los cultivos principales se encuentran 23 etnoespecies de "papa andina" [Solanum tuberosum subsp. andigena (Juz. \& Bukasov) Hawkes], 8 de "maíz" (Zea mays L.), 5 de "oca" (Oxalis tuberosa Molina), 5 de "papa verde o lisas" (Ullucus tuberosus Caldas), "haba" (Vicia faba L.), "arveja" (Pisum sativum L.) y "poroto" (Phaseolus vulgaris L.) (Tabla 2 y Fig. 5). Asimismo, se han incorporado especies hortícolas exóticas como legumbres y verduras de hoja (Tabla 3 ).

La fertilidad de las parcelas se mantiene a través de las prácticas de abonado con guano animal, rotación de cultivos y descanso del suelo (Fig. 5). La tecnología de labranza es heredada del modelo tradicional español con tracción animal, la manufactura es artesanal (Fig. 5). Esto limitó la continuidad del uso de andenes de cultivo característicos de las culturas andinas, que de forma paulatina se abandonaron o unieron para crear parcelas más amplias que facilitan la circulación con animales (Reboratti, 1998), sólo quedan sitios abandonados de esta forma de producción prehispánica.

El abastecimiento de semillas y propágulos depende generalmente de la autoproducción $\mathrm{y}$ el intercambio con vecinos, o bien su adquisición en ferias locales o regionales. La movilidad de los productores y el acceso a centros urbanos constituye una fuente de abastecimiento de nuevas especies; junto a la provisión de semillas de hortalizas del Programa Pro Huerta.

En espacios cercanos a las viviendas se encuentran las huertas y jardines donde se cultivan y mantienen especies aromáticas y medicinales estacionales o permanentes. Si el clima lo permite, también se encuentran árboles frutales, siendo los más importantes el "duraznero" [Prunus persica (L.) Batsch.] reproducido localmente por semillas, el "manzano" (Malus domestica L.), los "cítricos" [Citrus limon (L.) Burm., C. reticulata Blanco, C. paradisi Macf., C. sinensis (L.) Osbeck] e "higuera" (Ficus carica L.).

En las huertas y jardines de la residencia de mayor importancia -entre las que ocupa la 
Tabla 2. Variedades locales registradas de los principales cultivos.

Table 2. Registered local varieties of the main crops.

\begin{tabular}{|c|c|c|}
\hline $\begin{array}{l}\text { Nombre } \\
\text { vulgar }\end{array}$ & Familia/Especie & Etnoespecies \\
\hline \multirow[t]{2}{*}{ Papa } & SOLANACEAE & \multirow{2}{*}{$\begin{array}{l}\text { Papa colorada, p. redonda blanca, p. redonda chacarera, } \\
\text { p. rosada, p. churqueña, p. runa, p. ojo de paloma, p. } \\
\text { manzana, p. novilla, p. collareja, p. negra, p. tuni rosada, p } \\
\text { tuni blanca, p. azul, p. morada, p. niña bonita, p. morocha, } \\
\text { p. navesia, p. holandesa, p. santa maría, p. guareña, p. } \\
\text { revolución, p. guindita. }\end{array}$} \\
\hline & $\begin{array}{l}\text { Solanum tuberosum subsp. } \\
\text { andigena (Juz. \& Bukasov) } \\
\text { Hawkes }\end{array}$ & \\
\hline \multirow[t]{2}{*}{ Oca } & OXALIDACEAE & \multirow{2}{*}{$\begin{array}{l}\text { Oca chilena, o. colorada gruesa, o. overita, o. amarilla, o. } \\
\text { roja, o. cizaña. }\end{array}$} \\
\hline & Oxalis tuberosa Molina & \\
\hline \multirow[t]{2}{*}{ Papa lisa } & BASSELACEAE & \multirow{2}{*}{$\begin{array}{l}\text { Papa lisa verde, p. lisa overita, p. verde overita, p. amarilla, } \\
\text { p. matizada. }\end{array}$} \\
\hline & Ullucus tuberosus Caldas & \\
\hline \multirow[t]{2}{*}{ Maíz } & POACEAE & \multirow{2}{*}{$\begin{array}{l}\text { Maíz capia blanco, m. capia amarillo, m. amarillo, m. } \\
\text { garrapata, m. morocho, m. morado, m. ocho rayas, m. } \\
\text { cubano, m. tucumano, m. pisincho. }\end{array}$} \\
\hline & Zea mays L. & \\
\hline
\end{tabular}
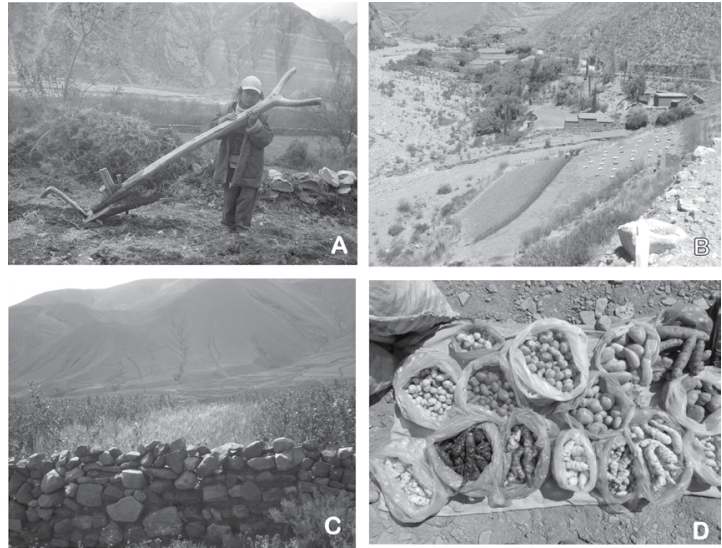

Fig. 5. A: Implemento de labranza, arado tradicional tirado por bovinos. B-C: Técnicas de cultivo en "rastrojos" y abonado con "guano". D: Etnovariedades de tubérculos de Oxalis tuberosa Molina en mercado local.

Fig. 5. A: Tillage implement, traditional plough pulled by bovines. B-C: Cultivation techniques in plots or "rastrojos" fertilized with manure or "guano". D: Ethnovariety of tubers of Oxalis tuberosa Molina in local market place.

UD- se observan especies medicinales silvestres nativas del ambiente de monte, que se reproducen a partir del cultivo en el ambiente de cerro. Tal es el caso del "anís del monte" (Peperomia collinsii Villa), la "siempre viva" (Peperomia tetraphylla Hook. \& Arn. y P. theodori Trel.) y el "nogal criollo" (Junglans australis Griseb.) para la obtención de sus nueces.
En las huertas se cultivan plantas de flor (ornamentales), entre las más usuales están "dalia" (Dhalia sp.), "rosa amarilla" y "terciopelo" (Tagetes patula L. y T. erecta L.), "gladiolo" (Gladiolus sp.), "cala" (Zantedeschia sp.), "clavel" (Dianthus caryophyllus L.), "caléndula" (Calendula officinalis L.), "cosmo" (Cosmos bipinnatus Cav.), "aroma" (Amaranthus cruentus L.), "estatice" [Limonium sinuatum (L.) Mill.], "conejito" (Antirrhinum majus L.), entre otros ejemplos. Para el festejo del día de las almas, celebración del 2 de noviembre basada en el recuerdo de las almas de los difuntos a través del agasajo con bebidas y comidas, se cultiva especialmente "cebolla" (Allium cepa L.) debido a que sus flores se utilizan para adornar las mesas con las ofrendas para las almas de los difuntos.

La recolección en el monte se practica durante las visitas a este ambiente, por las características de la vegetación allí presente, se pueden colectar las partes empleadas de cada especie durante todo el año. Se recolectan nueces de "nogal criollo" y maderas aptas para carpintería; se busca y prepara la madera para llevar al cerro, donde se hacen pequeños trabajos de carpintería. El invierno, en el monte (junio-agosto) es la época de recolección de cítricos que se encuentran naturalizados en ese ambiente. También se colecta "tomate del monte" [Cyphomandra 
betaceae (Cav.) Sendtn.], "querusilla" (Gunnera apiculata Schindl.) y especies medicinales como la "uña de gato" [Macfadyena ungis-cati (L.) A. H. Gentry], "kaleguala" (Pleopletis sp. y Microgramma sp.), "anís del monte", "siempreverde", "mil hombres" (Aristolochia sp.), "ají criollo" (Capsicum spp.).

El período de recolección en el cerro y el valle se da cuando la vegetación natural rebrota luego de las lluvias de verano (febrero-abril); el repertorio de especies que se recolectan en estos ambientes es más extenso y variado: especies aromáticas, medicinales y saborizantes se recolectan y se secan para su conservación y venta o trueque en los circuitos comerciales locales.

\section{Conocimientos sobre las etnoespecies}

Se ha registrado un total de 201 etnoespecies que pertenecen a 53 familias botánicas, las más importantes en cantidad de taxa citadas fueron: Asteraceae (34), Poaceae (26), Fabaceae y Solanaceae (13) y Lamiaceae (11). Con un menor número de etnoespecies mencionadas se encuentran: Amaranthaceae, Rosaceae y Rutaceae (8 cada una), Curcubitaceae (6), Verbenaceae (5), Apiaceae y Bromeliaceae (4 cada una). Las restantes familias registran tres o menos etnoespecies cada una. La predominancia de las familias Asteraceae y Poaceae, puede deberse localmente al hecho de que son usuales en Puna, Prepuna, praderas y bosques de Yungas.

El uso más reconocido es el medicinal con 81 etnoespecies $(40,3 \%)$, le siguen en importancia las forrajeras silvestres con 74 etnoespecies $(36,8 \%)$ y en tercer lugar las comestibles cultivadas con 38 etnoespecies $(18,9 \%)$. Las etnoespecies empleadas como saborizantes y/o condimento alcanzaron las 27 etnotaxa $(13,43 \%)$, y aquellas con usos rituales y/o ornamentales fueron 26 (12,9\%) (Fig. 6).

La categoría medicinal registró el número más elevado de etnoespecies, ya que los vegetales en la etnomedicina local poseen un fuerte anclaje como recurso para el tratamiento y prevención de las enfermedades. El conocimiento del repertorio de vegetales medicinales es amplísimo, su transmisión es oral e incorpora etnoespecies que no son nativas. Esta categoría se relaciona con la de saborizantes y/o condimentos, entre ambas categorías representan un universo del $53 \%$, con etnoespecies reconocidas solamente como medicinales junto a aquellas que por su aroma y/o su sabor también son utilizadas para saborizar infusiones y condimentar alimentos. Etnoespecies de ambas categorías pueden ser consumidas solas o agregadas a infusiones y comidas, como una práctica preventiva usual, sin que la persona se encuentre necesariamente bajo ningún tratamiento.

Las categorías referidas a forraje (forrajeras silvestres y forrajeras cultivadas), alcanzan el $39,8 \%$ de las etnoespecies; lo que muestra que la alimentación del ganado constituye un aspecto de gran relevancia. La categoría que engloba las etnoespecies tóxicas para el ganado $(9 \%)$ se encuentra también vinculada a su alimentación. Es así que el total de categorías vinculadas a la ganadería (forrajeras silvestres, forrajeras cultivadas y plantas tóxicas) alcanza el 48,8\% y suma 101 etnoespecies.

Las etnoespecies comestibles representan el $16 \%$, si se consideran tanto las cultivadas (13\%) como las silvestres recolectadas (3\%). En el ambiente de cerro la recolección de etnoespecies comestibles es mínima, ya que allí se concentra la actividad agrícola; mientras que en el monte se torna fundamental.

La categoría que agrupa aquellas etnoespecies vinculadas a la ritualidad local (13\%) se refiere a aquellas que pueden constituir ornamentos de los espacios o ámbitos donde se desarrolla la espiritualidad tradicional, y encontrarse también en instancias vinculadas a festejos y juegos. Tal es el caso de los ramos de flores que se prepararan para adornar diferentes acontecimientos, como también los vegetales que son considerados como parte integral de algún ritual local. A pesar de que se han registrado estos usos, se observa el ingreso de artículos comerciales plásticos y de tela, que podrían ocasionar cambios en el uso de vegetales para la ornamentación.

La categoría de etnoespecies empleadas como combustibles representan un menor aporte (7\%), esto se debe a que la forma más usual de cocción de los alimentos en las residencias permanentes, son las cocinas a gas o eléctricas. Es en la trashumancia al monte cuando el uso del fuego adquiere relevancia para preparación de alimentos. Sin embargo, en el cerro y el valle aún se emplea la leña como combustible para 
Tabla 3. Principales plantas alimenticias cultivadas en parcelas, rastrojos y huertas.

Table 3. Main food crops cultivated in plots, stubbles and orchards.

\begin{tabular}{|c|c|c|c|c|c|}
\hline $\begin{array}{l}\text { Nombre } \\
\text { vulgar }\end{array}$ & Especie & Familia & Parte utilizada & Siembra & Cosecha \\
\hline Acelga & Beta vulgaris var. cicla & AMARANTHACEAE & Tallos y hojas & Oct.-Nov. & Dic.-Feb. \\
\hline Ají morrón & Capsicum annuum & SOLANACEAE & Frutos & Oct.-Nov. & Dic.-Feb. \\
\hline Albahaca & Ocimun basilicum & LAMIACEAE & Tallos y hojas & Oct.-Nov. & Ene.-Feb. \\
\hline Angolino & Cucurbita moschata & CURCUBITACEAE & Frutos & Oct.-Nov. & Mar.-Ab. \\
\hline Apio & Apium graveolens & APIACEAE & Tallos y hojas & Oct.-Nov. & Feb.-Mar. \\
\hline Arvejas & Pisum sativum & LEGUMINOSAE & Frutos & Ago.-Nov. & Dic.-Mar. \\
\hline Cayotes & Pepo ficifolia & CUCURBITACEAE & Frutos & Nov.-Dic. & Mar.-Abr. \\
\hline Cebolla & Allium cepa & LILIACEAE & Bulbos y hojas & Ago.-Set. & Nov.-Dic. \\
\hline Girasol & Helianthus annuus & COMPOSITAE & Semillas & Ago.-Set. & Feb.-Mar. \\
\hline Habas & Vicia faba & LEGUMINOSAE & Frutos & Ago.-Set. & Feb.-Mar. \\
\hline Maíz & Zea mays & POACEAE & Frutos & Ago.-Set. & Feb.-Mar. \\
\hline Ocas & Oxalis tuberosa & OXALIDACEAE & Raíz tuberosa & Oct.-Nov. & Mar.-Abr. \\
\hline Papa andinas & $\begin{array}{l}\text { Solanum tuberosum } \\
\text { ssp. andigena }\end{array}$ & SOLANACEAE & Tubérculos & Ago.-Oct. & Feb.-Mar. \\
\hline Papa verde & Ullucus tuberosus & BASSELACEAE & Tubérculos & Ago.-Oct. & Feb.-Mar. \\
\hline Porotos & Phaseolus vulgaris & LEGUMINOSAE & Frutos & Ago.-Set. & Feb.-Mar. \\
\hline Quinua & Chenopodium quinua & CHENOPODIACEAE & Hojas y semillas & Set.-Oct. & Abr.-May. \\
\hline Remolacha & Beta vulgaris & AMARANTHACEAE & Bulbos & Oct.-Nov. & Dic.-Feb. \\
\hline Tomate & Solanum lycopersicum & SOLANACEAE & Frutos & Oct.-Nov. & Feb.-Mar. \\
\hline Yacón & $\begin{array}{l}\text { Smallanthus } \\
\text { sonchifolius }\end{array}$ & ASTERACEAE & Tubérculo & Nov.-Dic. & Mar.-Abr. \\
\hline Zanahoria & Daucus carota & APIACEAE & Raíz tuberosa & Set.-Oct. & Ene.-Feb. \\
\hline $\begin{array}{l}\text { Zapallito } \\
\text { verde }\end{array}$ & $\begin{array}{l}\text { Cucurbita maxima var. } \\
\text { zapallito }\end{array}$ & CURCUBITACEAE & Frutos & Nov.-Dic. & Ene.-Mar. \\
\hline Zapallo & Curcubita maxima & CURCUBITACEAE & Frutos & Nov.-Dic. & Mar.-Abr. \\
\hline
\end{tabular}

calentar los hornos de pan y en preparaciones largas que se mantienen en las brasas por varias horas como "puimar" granos de maíz, práctica que consiste en hervir los granos con vegetales utilizados como saborizantes para que adquieran sabor, para luego ser consumidos en diferentes preparaciones.

La categoría vinculada a la construcción y maderables $(3 \%)$ está poco representada por la escasez de etnoespecies arbóreas en el ambiente de cerro y de valle; el acceso a estos recursos se restringe al ambiente del monte, donde se encuentran las principales etnoespecies empleadas en carpintería y construcción. Por último, la categoría utensilios domésticos $(3 \%)$ muestra también una baja representación, probablemente por cambios en el acceso a productos comerciales, como implementos de cocina y vajilla.

\section{Discusión y Conclusiones}

La organización de las prácticas de manejo del paisaje y de los recursos vegetales de las unidades domésticas debe ser analizada en 


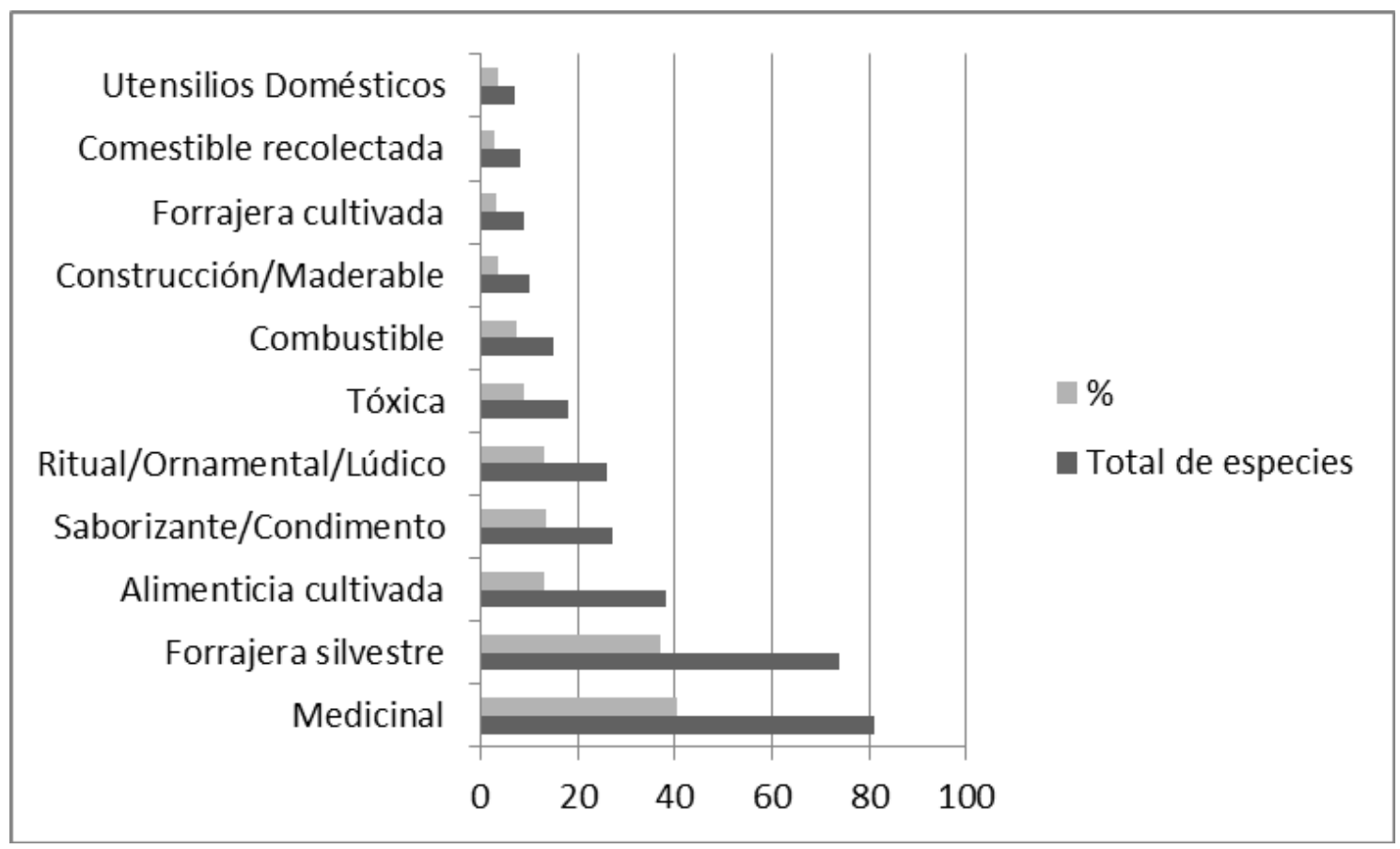

Fig. 6. Número y porcentaje de etnoespecies según categoría de uso.

Fig. 6. Number and percentage of ethnospecies by use category.

función de los movimientos entre las UP cerro, valle y monte, lo cual muestra que existe una percepción o clasificación local que es similar a la ya registrada por otros investigadores en zonas aledañas de la cordillera oriental (Sturzenegger, 1982; Hilgert, 1998, 1999, 2001, 2004, 2007a, b). Esto se complementa con un ciclo anual estructurado por los períodos de sequedad y de precipitaciones, que determinan los momentos en que se realiza cada práctica productiva, de subsistencia y ritual. Para áreas aledañas se señala también el uso del concepto de tiempos para denominar los meses en que se realizan a festejos en el cerro cuando la hacienda se encuentra en esa UP. El manejo del paisaje entre los ambientes de cerro, valle y monte brinda al sistema de vida local diferentes recursos vegetales y posibilidades, conformando un sistema de uso complementario a través de las prácticas de manejo de los recursos que se realizan en cada uno. Las actividades que despliega la UD determinan una doble morfología social, con un modo de vida durante el período invernal que transcurre en el monte y otro diferente a la época estival que trascurre en el cerro, como lo planteara Sturzenegger (1982).

Las prácticas de manejo de los recursos vegetales identificadas son: a) agrícolas, realizadas en parcelas o rastrojos destinadas al cultivo de etnoespecies comestibles (nativas e introducidas) y forrajeras (solo introducidas); b) de jardinería, en huertas y jardines domésticos de las viviendas, para el cultivo de etnoespecies comestibles (frutales), medicinales, saborizantes y condimentos; c) de recolección, en cerro y monte, para la obtención de etnoespecies comestibles, maderables, medicinales, saborizantes y condimentos; d) de pastoreo y trashumancia, con movimientos entre el cerro y el monte, para empleo anual de diferentes fuentes forrajeras y e) comerciales, para la obtención de recursos vegetales procedentes de otros ambientes a través del trueque, venta e intercambio de las etnoespecies (tanto en estado vegetativo como conservadas).

En tal sentido, se observa que estas prácticas pueden originar como resultado un paisaje cultural; por su aplicación 
histórica, de forma continuada, individual y comunitaria, que incluyen también: manejo sucesional (pastoreo), aprovechamiento de la heterogeneidad ambiental (manejo vertical/ pastoreo/trashumancia), domesticación (cultivo de especies procedentes de diferentes ambientes), transformación del paisaje (agricultura) y un manejo múltiple de los recursos vegetales (Davidson-Hunt et Berkes, 2003; Toledo et Bassols, 2008; Caparelli et al., 2011; Lema et Pochettino, 2012).

La trashumancia es una de las prácticas que más impacto posee en la subsistencia de los campesinos, se constata el uso vertical del ambiente, descripto por Troll (1935) y Murra (1972) para sociedades andinas. Una similar estructura en el ciclo anual y estrategia de uso vertical del ambiente también fueron señaladas por Sturzenegger (1982), Levy Hynes (1994), Hilgert (1998, 2000, 2001, 2007a, b), Reboratti (1998), y Quiroga Mendiola (2000), para comunidades del NE de la provincia de Salta pertenecientes a la cuenca del río Bermejo, al igual que Iruya. Así, se corrobora la vigencia del esquema general trashumante planteado para la $\mathrm{CO}$ en la provincia de Salta, probablemente debilitado por la sedentarización de las unidades domésticas en el ambiente de cerro o la migración fuera del territorio. Por su parte, Hilgert et Gil (2005) advertían procesos de sedentarización en residencias estables conjuntamente con una disminución del uso vertical del ambiente, para comunidades de Yungas del N del departamento Santa Victoria en la provincia de Salta. Tal como refieren Ventura et Belardi (2001) e Hilgert (1998) para otras comunidades de la Alta Cuenca del Río Bermejo, el acceso a estas poblaciones es sumamente dificultoso, aspecto que redunda en un aislamiento geográfico significativo en amplios sectores del territorio. Por ello, la mayor cantidad de población del territorio se concentra en el ambiente de cerro, siendo el monte una UP esencial en el uso vertical del ambiente pero no como sitio de residencia. La UP de cerro funciona simultáneamente como espacio residencial, social y agrícola; mientras que el monte tiene usos vinculados al aprovechamiento de la diversidad de recursos vegetales, a través de la ganadería y de la recolección. Es el esquema de uso ganadero extensivo (a escala territorial), la multiplicidad de residencias de las UD, la diversidad de recursos proveniente de ambientes diferentes lo que permite maximizar las posibilidades reproductivas de las familias campesinas; a partir de estas estrategias, se genera un conjunto de bienes locales necesarios para la subsistencia.

La diversidad de prácticas de manejo del paisaje que realizan los pobladores de Iruya se encuentra facilitada por los factores que ya fueron considerados por Reboratti (1998) para toda la Alta Cuenca del Río Bermejo: a) la disponibilidad de variedad ambiental, que permite el uso o manejo vertical de los ambientes, b) la tenencia del territorio, lo que permite la toma de decisiones de uso del paisaje y de los recursos vegetales, y c) un sistema de intercambio de los bienes por redes locales a través del trueque.

Las estrategias de gestión del territorio y los recursos se basan en la cosmovisión tradicional, en la cual la naturaleza (representada por la Pachamama) es central como dadora de condiciones favorables para la vida, con lo cual se tiende a asumir con responsabilidad el manejo de los recursos naturales. A raíz de esto, hay una fuerte cohesión entre las prácticas agropecuarias y la religiosidad: toda actividad agropecuaria se encuentra ligada a lo ritual. Esto lleva a implementar cuidados particulares en las prácticas productivas, de manera de congraciarse con la deidad y conseguir condiciones ambientales positivas. Se ha encontrado una amplia coincidencia en cuanto a los rituales y festividades religiosas, con las señaladas por Sturzenegger (1982) y Hilgert (1998) para comunidades aledañas. El rol de este tipo de cosmovisiones que implican creencias y prácticas ecológicamente más correctas ya fue señalado por otros autores para diferentes sociedades tradicionales de otras partes del mundo (Toledo, 1992; Berkes et al., 2000; Berkes et Davidson-Hunt, 2006; Toledo et Barrera Bassols, 2008).

Se puede considerar que los campesinos trashumantes de Iruya manejan y estructuran un paisaje; esto es aún posible por la conservación de la diversidad biocultural propia de estas sociedades; como lo plantean Capparelli et al. 
(2011) constituye un aspecto a tener en cuenta para la valoración de las culturas locales del pasado y del presente de la Argentina, que cumplen roles como diversificadoras de paisajes y/o como generadoras de estrategias de uso del ambiente que están o estuvieron en sintonía con la protección de la naturaleza.

Finalmente, se plantea que el conocimiento tradicional de los recursos vegetales vinculados a prácticas productivas, y asociado al uso del paisaje en esquemas como la trashumancia, constituye una base indispensable para la planificación del desarrollo local de estas sociedades y la conservación de la diversidad biocultural de los ambientes. El desafío es acercar los conocimientos científicos y los saberes tradicionales en la búsqueda del equilibrio entre el bienestar de los habitantes y la conservación de los recursos (LagosWitte et al., 2011).

\section{Agradecimientos}

A los pobladores de Iruya por compartir su tiempo y sus relatos. A Pastor Arenas por su dedicada dirección de la tesis doctoral. A Fernando Echazú, Bárbara Bartl y César Herrera por su compañerismo y cooperación en las diferentes etapas de la investigación. A los revisores por sus sugerencias al trabajo que lo ha mejorado significativamente. Al INTA por el acompañamiento financiero y logístico.

\section{Bibliografía}

ALBUQUERQUE, U. P., A. L. B. NASCIMENTO, G. T. SOLDATI, I. S. FEITOSA, J. L. A. CAMPOS, J. A. HURRELL, N. HANAZAKI, P. M. MEDEIROS, R. R. VASCONCELOS DA SILVA, R. H. LUDWINSKY, W. S. F. JÚNIOR \& V. REYESGARCÍA. (2019). Ten important questions/issues for ethnobotanical research. Acta Botanica Brasilica 33: 376-385.

http://dx.doi.org/10.1590/0102-33062018abb0331

ARCHETTI, E. P. \& K. A. STÖLEN. (1975). Explotación familiar y acumulación de capital en el campo argentino. Serie: Sociología y Política. Ed. Siglo Veintiuno. Buenos Aires, Argentina.
ARENAS, P. \& N. M. KAMIENKOWSKI. (2014). La documentación del material vegetal incompleto o fragmentario en la investigación etnobotánica. Ed. ProBiota (FCNyM, UNLP). Técnica y Didáctica 26: 1-17. La Plata, Argentina.

ARENAS, P. \& G. J. MARTÍNEZ. (2012). Estudio etnobotánico en regiones áridas y semiáridas de Argentina y zonas limítrofes. En ARENAS, P. (ed.), Etnobotánica en regiones áridas y semiáridas del Cono Sur de Sudamérica, pp. 11-43. Edición del CEFYBO-CONICET. Buenos Aires, Argentina.

BAPTISTA LUCIO, M. P., C. F. COLLADO \& R. H. SAMPIERI. (2006). Metodología de la Investigación. Ed. McGraw-Hill Interamericana. México.

BARTL, B. (2019). "La yaquispala": prácticas locales, memoria y conservación. Boletín de la Sociedad Argentina de Botánica 54: 451-471.

BENDINI, M., P. TSAKOUMAGKOS \& B. DESTEFANO. (1993). El trabajo trashumante. En Grupo de Estudios Sociales Agrarios (ed.), Campesinado y ganadería trashumante en Neuquén, pp. 1-78. Ed. La Colmena. Buenos Aires, Argentina.

BENDINI, M., P. TSAKOUMAGKOS \& C. NOGUES. (2004). Los crianceros trashumantes del Neuquén. En BENDINI, M. \& C. ALEMANY (comp.), Crianceros y chacareros en la Patagonia, pp. 2340. Ed. Colmena (Cuadernos GESA, 5-INTANCRCRD). Buenos Aires, Argentina.

BERKES, F. \& I. J. DAVIDSON-HUNT. (2006). Biodiversity, traditional management systems, and cultural landscapes: examples from the boreal forest of Canada. International Social Science Journal 58: 35-47.

BERKES, F., J. COLDING \& C. FOLKE. (2000). Rediscovery of traditional ecological knowledge as adaptive management. Ecological applications 10: 1251-1262.

BIANCHI, A. R. \& C. E. YÁNEZ. (1992). Las precipitaciones del Noroeste Argentino. Ed. INTA Salta, Argentina.

BOCCO DE ABEYÁ, A. (1988). Contribución al Conocimiento del Espacio Social Pastoral de Subsistencia. Cuadernos de Antropología Social 1: 79-95.

CABRERA, A. L. (1976). Regiones Fitogeográficas Argentinas. Enciclopedia Argentina de agricultura y jardinería. Ed. Acme. Buenos Aires, Argentina.

CABRERA, A. L. \& A. WILLINK. (1980). Biogeografía de América Latina. $2^{\mathrm{a}}$ edición corregida. Monografía 13. Serie de Biología. Secretaría General de la Organización de los Estados Americanos. Washington DC. EEUU. 
CÁCERES, D. (2003). El campesinado contemporáneo. En THORNTON, R. \& G. CIMADEVILLA (ed.), La extensión rural en debate: Concepciones, retrospectivas, cambios y estrategias para el Mercosur (No. C20/2), pp. 173-197. Instituto Nacional de Tecnología Agropecuaria, Buenos Aires, Argentina.

CALIFANO, M. L. (2019). Conocimiento tradicional y manejo de los recursos vegetales en productores campesinos trashumantes de ganado bovino en Iruya (Salta, Argentina). Tesis Doctoral Facultad de Ciencias Agrarias, Universidad Nacional del Nordeste. Corrientes, Argentina.

CALIFANO, L. M. \& F. ECHAZÚ. (2013). Etnobotánica en comunidades pastoriles. Conocimiento tradicional sobre especies tóxicas para el ganado en la cuenca del río Iruya (Salta, Argentina). Boletín de la Sociedad Argentina de Botánica 48: 365-375.

CAPPARELli, A., N. HILGERT, A. LADIO, V. S. LEMA, C. LLANO, S. MOLARES, M. L. POCHETTINO \& P. STAMPELLA. (2011). Paisajes culturales de Argentina: pasado y presente desde las perspectivas etnobotánica y paleoetnobotánica. Revista de la Asociación Argentina de Ecología de Paisajes 2: 67-79.

COTTON, C. (1996). Ethnobotany: principles and applications. Ed. John Wiley and Sons, Chichester, England.

DAVIDSON-HUNT, I. \& F. BERKES. (2003). Learning as you journey: Anishinaabe perception of socialecological environments and adaptive learning. Conservation Ecology 8: 5.

ECHAZU, F., L. M. CALIFANO, R. PAZ. \& C. HERRERA. (2013). Estrategias de la ganadería campesina en Iruya (Salta - Argentina). VII Jornadas Interdisciplinarias de Estudios Agrarios y Agroindustriales. Actas en CD-ROM ISSN 18513794. Universidad de Buenos Aires, Argentina.

ECHAZÚ, F., L. M. CALIFANO \& C. HERRERA. (2016). La ganadería bovina en sistemas campesinos de las comunidades de Iruya (Salta) - Abordaje de saberes, conocimientos y relevancia local. PreCongreso ALASRU (Asociación Latinoamericana de Sociología Rural). Santiago del Estero, Argentina.

ESCOLAR, D. (1996). Prácticas espacio-temporales, poder e identidad entre los baqueanos de los Andes Sanjuaninos. Cuadernos del Instituto Nacional de Antropología y Pensamiento Latinoamericano 17: 17-39.

GALAFASSI, G. P. (1994). Manejo y apropiación del medio natural por una comunidad de pastores de altura (Laguna Blanca-Catamarca). Ruralia 5: 7-25.
GÖBEL, B. (2001). El ciclo anual de la producción pastoril en Huancar (Jujuy, Argentina); En MENGONI GOÑALONS, G., D. OLIVERA \& H. YACOBACCIO (ed.), El uso de los camélidos a través del tiempo, pp. 91-115. Ed. El Tridente, Buenos Aires.

GÖBEL, B. (2002). La arquitectura del pastoreo: Uso del espacio y sistema de asentamientos en la Puna de Atacama. Estudios Atacameños 23: 53-76.

GRECO, M. G. (1995). Iruya: migración temporaria y reproducción campesina. Boletín de estudios geográficos 25: 733-740.

GRIMALDI, P. A. \& C. TRILlO. (2018). Prácticas y usos tradicionales de "cerco" y "monte" por los criollos de San Marcos Sierras (Córdoba, Argentina). Bonplandia 27: 81-98.

HILGERT, N. I. \& G. E. GIL. (2005). Traditional andean agriculture and changing processes in the Zenta river basin, Salta, Northwestern Argentina. Darwiniana 43: 30-43.

HILGERT, N. I. (1998). Las plantas vinculadas con el ámbito doméstico y la subsistencia de los campesinos de la cuenca del río Zenta, Dpto. Orán, Prov. Salta (Tesis Doctoral. Universidad Nacional de Córdoba, Argentina).

HILGERT, N. I. (1999). Las plantas comestibles en un sector de las Yungas meridionales (Argentina). Anales del Jardín Botánico de Madrid 57: $117-$ 138.

HILGERT, N. I. (2001). Plants used in home medicine in the Zenta river basin, Northwest Argentina. Journal of Ethnopharmacology 76: 11-34.

HILGERT, N. I. (2004). Las plantas en las festividades religiosas de la selva andina argentina. Société Suisse des Américanistes 68: 37-49.

HILGERT, N. I. (2007a). La vinculación del hombre actual con los recursos naturales y el uso de la tierra. En BROWN, A. D., M. G. MORITÁN, B. VENTURA, N. HILGERT \& L. MALIZIA (eds.), Finca San Andrés: un espacio de cambios ambientales y sociales en el Alto Bermejo, pp. 159-186. Ed. del Subtrópico, Fundación ProYungas, Tucumán, Argentina.

HILGERT, N. I. (2007b). Plantas silvestres, ámbito doméstico y subsistencia. En Finca San Andrés. En BROWN, A. D., M. G. MORITÁN, B. VENTURA, N. I. HILGERT \& L. MALIZIA (eds.), Finca San Andrés: un espacio de cambios ambientales y sociales en el Alto Bermejo, 187228. Ed. del Subtrópico, Fundación ProYungas, Tucumán, Argentina. 
HOCSMAN, L. D. (2011). Estrategias territoriales, re-campesinización y etnicidad en los Andes de Argentina. Ed. Consejo Latinoamericano de Ciencias Sociales - CLACSO. http:// biblioteca.clacso.edu.ar/ar/libros/coedicion/ EstrategiasTerritoriales.pdf

HOOFT, K. V. (2004). Gracias a los animales: análisis de la crianza pecuaria familiar en Latinoamérica, con estudios de caso en los Valles y el Altiplano de Bolivia. Ed. Plural, AGRUCO. La Paz, Bolivia.

IBODA. (2019). Instituto de Botánica Darwinion. Flora del Cono Sur Catálogo de Plantas Vasculares. Disponible: http://www2.darwin.edu.ar/Proyectos/ FloraArgentina (Consulta 10/19).

INDEC. (2010). Instituto Nacional de Estadística y Censos. Censos Nacionales de Población, Hogares y Viviendas 2001, 2010. Disponible: http://www. indec.gov.ar (Consulta 10/19).

LAGOS-WITTE, S., O. L SANABRIA DIAGO, P. CHACÓN \& R. GARCÍA. (2011). Manual de herramientas etnobotánicas relativas a la conservación y el uso sostenible de los recursos vegetales. Red Latinoamericana de Botánica. http:// www.ibiologia.unam.mx/gela/manualetnobot.pdf

LAMBARÉ, A. \& M. L. POCHETTINO. (2012). Diversidad local y prácticas agrícolas asociadas al cultivo tradicional de duraznos, Prunus persica (Rosaceae), en el noroeste de Argentina. Darwiniana 50: 174-186.

LEMA, V. \& M. L. POCHETTINO. (2012). Cambio y continuidad al plato: los saberes culinarios y su rol en la dinámica de la diversidad biocultural. En BABOT, M. P., M. MARSCHOFF \& F. PAZZARELLI (eds.), Las manos en la masa: arqueologías, antropologías e historias de la alimentación en Suramérica, pp. 25-46.

LEVY HYNES, A. (1994). Uso de las plantas por las comunidades campesinas de las Yungas del extremo norte de Argentina. Facultad de Ciencias Naturales e Instituto Miguel Lillo, Universidad Nacional de Tucumán, Curso de entrenamiento de la Carrera de Ciencias Biológicas. Ed. LIEY, FCN e IML, Universidad Nacional de Tucumán, Argentina.

MAFFIA, M. M. \& B. ZUBRZYCKI. (1999). Parentesco y organización familiar en una comunidad rural del valle de Hualfín, Catamarca. Ponencia presentada en III RAM, Reunión de Antropología del MERCOSUR. Departamento de Antropología Social de la Universidad Nacional de Misiones, Posadas, Argentina.
MAPINDUZI, A. L., G. OBA, R. B. WELADJI \& J. E. COLMAN. (2003). Use of indigenous ecological knowledge of the Maasai pastoralists for assessing rangeland biodiversity in Tanzania. African Journal of Ecology 41: 329-336.

MARTÍNEZ, M. (2006). La investigación cualitativa (Síntesis conceptual). Revista de Investigación en Psicología 9: 123-146.

MERLINO, R. \& M. RABEY. (1983). Pastores del altiplano andino meridional: Religiosidad, territorio y equilibrio ecológico. Allpanchis 21: 149-171.

MURRA, J. V. (1975). El control vertical de un Máximo de Pisos Ecológicos en la Economía de las Sociedades Andinas. En MURRA, J. V. (ed.), Formaciones Económicas y Políticas del Mundo Andino, 59-116 pp. Ed. Instituto de Estudios Peruanos. Lima, Perú.

NIELSEN, A. E. (1996). Demografía y cambio social en Quebrada de Humahuaca (Jujuy, Argentina) 7001535 d. C. Relaciones de la Sociedad Argentina de Antropología 21: 307-354.

QUIROGA MENDIOLA, M. (2000). Condición actual de los pastizales de altura y sistema de pastoreo en los valles intermontanos de la Cordillera Oriental. Departamento de Iruya, Salta. Tesis de Maestría en Desarrollo de Zonas Aridas y Semiáridas Universidades del NOA, Salta, Argentina.

RAFFAELLI, S. \& F. PÉREZ AYALA. (1999). Programa de manejo integrado de la cuenca del rio Iruya. Ed. COREBE. FMAM - OEA - PNUMA. Salta, Argentina.

RAGONESE, A. E. (1967). Vegetación y ganadería en la República Argentina. Colección Científica del INTA. Ed. Instituto Nacional de Tecnología Agropecuaria.

REBORATTI, C. (1998). El Alto Bermejo realidades y conflictos. Ed. La Colmena. Buenos Aires.

REINOSO, M. O. D. G. \& B. RUTHSATZ. (1982). Environment, human settlement and agriculture in the Puna of Jujuy, Argentina: a case study of land use change. Mountain Research and Development 2: 111-126.

RÍOS OCSA, B. (1992). Ganadería y economía campesina. La importancia de los animales en los sistemas tradicionales de producción en la Sierra Sur de Cusco. Trabajos del Colegio Andino (12), Ed. Centro de Estudios Regionales Andinos Bartolomé de las Casas. Cuzco, Perú.

ROSALES-BUSTAMANTE, E. P., C. D. C. LUNAMORALES \& A. CRUZ-LEÓN. (2009). Clasificación y selección tradicional de pitaya [Stenocereus pruinosus (Otto) Buxb.] en Tianguistengo, Oaxaca y variación morfológica de cultivares. Revista Chapingo. Serie Horticultura, 15: 75-82. 
SÁNCHEZ, M., P. MIRAÑA \& J. DUIVENVOORDEN. (2007). Plantas, suelos y paisajes: ordenamientos de la naturaleza por los indígenas Miraña de la Amazonía colombiana. Acta Amazónica 37: 567-582.

SCARPA, G. F. (2000). Estudio etnobotánico de la subsistencia de los criollos del oeste de Formosa. Tesis Doctoral, Facultad de Ciencias Exactas y Naturales. Universidad de Buenos Aires, Argentina.

SCARPA, G. F. 2007. Etnobotánica de los Criollos del oeste de Formosa: Conocimiento tradicional, valoración y manejo de las plantas forrajeras. Kurtziana 33: 153-174.

STURZENEGGER, O. (1982). Área de la selva Tucumano-Oranense. San Andrés: Actividades de subsistencia tradicionales y ritual propiciatorio. Documenta Laboris 27. Ed. Programa de Investigaciones sobre Epidemiología Psiquiátrica, CONICET. Buenos Aires, Argentina.

SUÁREZ, M. E. (2014). Etnobotánica wichí del bosque xerófito en el Chaco Semiárido salteño. Ed. Autores de Argentina. Buenos Aires, Argentina.

THE PLANT LIST. (2013). A working list of all plant species diversity. Disponible: http://www. theplantlist.org/ (Consulta 10/19).

TOLEDO, V. M. (1992). La racionalidad ecológica de la producción campesina. En SEVILLA GUZMÁN, E. \& M. GONZÁLES DE MOLINA (eds.), Ecología, campesinado e historia. Ed. La Piqueta, Madrid.

TOLEDO, V. M. (2002). Ethnoecology: a conceptual framework for the study of indigenous knowledge of nature. Ethnobiology and biocultural diversity, 2014: 511-522.

TOLEDO, V. M. \& N. BARRERA BASSOLS. (2008). La memoria biocultural: la importancia ecológica de las sabidurías tradicionales, vol. 3. Ed. Icaria. Barcelona.

TORRADO, S. (1981). Sobre los conceptos de "estrategias familiares de vida" y "proceso de reproducción de la fuerza de trabajo". Notas teórico-metodológicas. Demografía y economía 15: 204-233.

TROLL, C. (1935). Los fundamentos de las civilizaciones Andinas y del Imperio Incaico. Revista Universitaria 8: 127-83.

TROLL, C. (1973). High mountain belts between the polar caps and the equator: their definition and lower limit. Arctic and Alpine Research 5: 19-27.

TROPICOS.ORG (2019) Missouri Botanical Garden. Disponible: http://www.tropicos.org/ (Consulta 05/10/19).

TSAKOUMAGKOS, P. (1993). Sobre el campesinado en Argentina. En POSADA, M. (ed.) Sociología Rural Argentina, pp.113-154. Ed. Centro Editor de América Latina. Buenos Aires, Argentina.

VENTURA, B. \& J. B. BELARDI. (2001). When clouds cover the woods: Etnoarchaeology in the Yungas of Salta, Argentina. En KUZNAR, L. (ed.), Etnoarchaeology of Andean South AmericaContributions to Archaeology Methods and Theory, pp. 67-83. Etnoarchaeological Series, 4. International Monographs in Prehistory Ann Arbor, Michigan.

YACOBACCIO, H., C. M. MADERO, M. P. MALMIERCA \& M. D. C. REIGADAS. (1998). Caza, domesticación y pastoreo de camélidos en la Puna Argentina. Relaciones de la Sociedad Argentina de Antropología 22: 389-418.

ZONNEVELD, I. (1989). The land unit - a fundamental concept in landscape ecology, and its applications. Landscape ecology 3: 67-86. 